\title{
Application of Labor Laws and Other Compliances in Readymade Garment Industry of Bangladesh
}

\author{
Nazrul Islam ${ }^{1, *}$, Sharmina Afrin ${ }^{1}$, Tafannum Tasnim ${ }^{2}$, Md. Pranto Biswas ${ }^{2}$, Tasnim Shahriar ${ }^{2}$ \\ ${ }^{1}$ School of Business, Uttara University, Dhaka, Bangladesh \\ ${ }^{2}$ Faculty of Business Studies, Bangladesh University of Professionals, Dhaka, Bangladesh
}

Copyright@2018 by authors, all rights reserved. Authors agree that this article remains permanently open access under the terms of the Creative Commons Attribution License 4.0 International License

\begin{abstract}
Although, the economy of Bangladesh is primarily dependent on agriculture, Readymade Garment (RMG) industry has emerged as the largest earner foreign currency of Bangladesh in recent years. More than $75 \%$ of foreign earnings are coming through export from this very important sector of Bangladesh. In study of Islam \& Chowdhuri, [1] presently more than four million workers are working in 4,500 RMG companies of Bangladesh in which $90 \%$ are illiterate women who are from the rural areas of the country. The policymakers and the employers of this sector claim that the growth of garment sector has helped employing a huge number of rural women that has subsequently developed their socioeconomic. But, it is a concern of the national and internal observers that the compliances like factory laws, industrial relations laws, employment laws, payment of wages laws, ILO standards, ethics applied in this sector are hardly followed by the RMG companies that make the lives of the workers very misery. Sometimes, the female workers are exploited by employing more hours a day without the payment of overtime by capitalizing their illiteracy and submissiveness. Hence, this paper aims at identifying the level of application of the labor laws and the compliances in RMG industry of Bangladesh that is the only protective measures of the large number of female workers of this sector of Bangladesh. A total of 238 workers of this sector were interviewed in this study with a structured questionnaire. Multivariate analysis techniques such as, Factor Analysis and Multiple Regression Analysis were used to analyze the data. Results show that in case of measures for protecting sexual harassment there is a severe problem of the use of the labor laws in this sector followed by physical movement and access control, exit and access path of the company, working hours, and counseling arrangements in the company. This study suggests that the readymade garment companies should address the sexual harassment issue seriously so that the workers will feel safe at their work. They also should focus more on the safety issues, working hours, and counseling of the workers in order to make the working environment more favorable to the
\end{abstract}

workers.

Keywords RMG Industry of Bangladesh, Safety and Security, Sexual Harassment, Working Hours, Workers Counseling

\section{Background}

Bangladesh is an agricultural country where most of the people are farmers. The main industry of Bangladesh was agro-based industry i.e., jute and other agricultural products at one time. Jute was called the golden fiber of Bangladesh as it brought most of the foreign earnings for the country. It was a wonderful crop of the whole world and highly demanded by the world community. But in early seventies, readymade garment industry started its journey with a few companies. In last three decades, readymade garment became the main earners of the country. Now, this industry is earning more than $75 \%$ of the foreign earnings of the country. Islam \& Muntaquimul Bari Chowdhuri’s [1] study shows today, more than four million workers are working in 4,500 RMG companies in which $90 \%$ workers are illiterate women who are from the rural areas of Bangladesh. Therefore, this sector has been working as the catalyst for the development of the economy of Bangladesh [2]. This sector is making substantial contributions to build the economy and the economic development of the millions of poor people of Bangladesh. Bangladesh with its limited resources has been maintaining consistently 6\% annual growth which is partly due to the development of this readymade garment industry. But this industry is not free from challenges. One of the biggest challenges currently faced by RMG industry is the workplace safety, sexual harassment at work, health and hygiene of the workers and acceptable working conditions for the millions of garment workers.

Needless to say that readymade garment products produced in Bangladesh are global products and the buyers 
have keen interest to get it ready from the developing countries like Bangladesh where labor cost is very low. For that reason, Bangladesh is the best place for the buyers where a plenty of cheap laborers are available. In addition, the legal and other compliances of World Trade Organization (WTO) and the International Labor Organization (ILO) have made it more favorable to source the garment products by the developed countries from the developing countries like Bangladesh. But the application of the compliances is very poor in these developing countries including Bangladesh. Hence, a serious concern has been raised by the buyers and the policymakers of this sector about the application of legal and other compliances of these fully export-oriented garment companies. Therefore, this study aims at identifying the legal and other compliances which are not properly addressed and applied by these readymade garment companies of Bangladesh.

\section{Objectives of the Study}

The overall objective of this study is to evaluate the application of legal and other compliances relevant to the readymade garment industry of Bangladesh. The specific objectives are:

1. To describe the legal issues applicable to readymade garment industry of Bangladesh;

2. To identify the areas or factors related to the legal and other compliances of readymade garment industry of Bangladesh;

3. To identify and explain the significant factors or areas concerning the legal aspects or other compliances of readymade garment industry of Bangladesh;

4. To provide some suggestions to the policymakers to improve the present situation of the readymade garment industry of Bangladesh.

\section{Research Methods}

This study aims at evaluating the application of legal and other compliances relevant to the readymade garment industry of Bangladesh. To conduct this study, primary and secondary data were used. Primary data were collected from the RMG workers and the secondary data were collected from the books, magazines, research monographs, and journals.

For this study, the garment workers selected from different departments of 12 RMG companies engaged in cutting, sewing, finishing and packaging jobs. These companies are located in Gazipur area of Dhaka which is popularly called as the hub of RMG companies of Bangladesh. To select the companies, size of the company based on the number of workers such as large, medium and small companies of Bangladesh. The total number of workers in the RMG sector of Bangladesh is more than
400,000 and the sample size was determined as 204 with $7 \%$ precision. However, 238 sample workers were interviewed in this study. The sample size of this study was determined by using the following formula suggested by Yamane [3].

$$
n=\frac{N}{1+N(e)^{2}}
$$

Where, $n$ is the sample size, $N$ is the population size, and $e$ is the level of precision. For this study, level of precision is presumed as 0.07 and the population size is 400,000 . Putting these values in the above equation, the required number of sample size becomes approximately 204. This study interviewed 238 female workers from twelve RMG companies of Bangladesh. This figure is well above the critical sample size of 200 for employing multivariate analysis like regression analysis [4].

A structured questionnaire was developed to collect information related to the legal and other compliances of readymade garment industry. The questionnaire was developed based on the "Bangladesh Labor Act 2006". This study mainly covered the issues such as, legal and social aspects, health and safety, work and environment, security, and other issues related to the topic (Appendix 2). The respondent workers opined on 36 attributes across the entire spectrum of working conditions and working lives of the workers. Responses to all the statements in the questionnaire were measured on a five-point scale ranging from 1 to 5 with 1 indicating strongly disagree and 5 indicating strongly agree. One of the relative advantages of using this scale is its suitability for the applications of multifarious statistical tools used in social research study [5]. The collected data were statistically processed subsequently to get the useful information.

Primary data were used for the purpose of the analysis whereas secondary data were collected for the background study. The survey was conducted among the female workers of twelve RMG companies which represent the main stream of RMG companies of Bangladesh. Along with descriptive statistics ${ }^{1}$, inferential statistical $^{2}$ techniques such as, Factor Analysis and Multiple Regression Analysis were used to analyze the data. A Principal Component Analysis (PCA) with an Orthogonal Rotation (Varimax) ${ }^{3}$ using the SPSS (Statistical Package

\footnotetext{
${ }^{1}$ Descriptive statistics includes statistical procedures that we use to describe the population we are studying. The data could be collected from either a sample or a population, but the results help us organize and describe data. Descriptive statistics can only be used to describe the group that is being studying. That is, the results cannot be generalized to any larger group.

${ }^{2}$ Inferential statistics is concerned with making predictions or inferences about a population from observations and analyses of a sample. That is, we can take the results of an analysis using a sample and can generalize it to the larger population that the sample represents.

${ }^{3}$ Varimax rotation is an orthogonal rotation of the factor axes to maximize the variance of the squared loadings of a factor (column) on all the variables (rows) in a factor matrix, which has the effect of differentiating the original variables by extracted factor. Each factor will tend to have either large or small loadings of any particular variable. A varimax solution yields results which make it as easy as possible to identify each
} 
for Social Sciences) was performed on the survey data. Multiple Regression Analysis ${ }^{4}$ was conducted to identify the relationships between the dependent and independent variables of the model.

\section{Literature Review}

For the last couple of decades, readymade garment industry of Bangladesh has been playing a pivotal role for the development of the economy. This sector accounts for nearly $75 \%$ of export earnings that is driving the economy of Bangladesh. This industry also provides jobs for hundreds of thousands semi-skilled and unskilled workers, who are mostly rural illiterate women. Although, the quota protection of RMG sector was withdrawn in 2004, it remained competitive due to cheap labor and the work quality of Bangladeshi workers. Study shows that both economic choices of cheap labor and gender orientation collaboratively contribute to feminizing the labor force in this sector. This feminization of the workforce, in fact, induced the violation of labor rights and benefits by the owners in this sector [6]. The alarming fact is that, the work place safety, health \& hygiene conditions in Bangladesh's RMG workers is lagging behind for lack of attention by the monitoring authority of the government. Due to lack of proper implementation of labor laws in this industry, labor unrest wreaked havoc on this sector and it became a regular phenomenon. The solution doesn't lie in merely apportioning blame to the external factors or seeking hidden clues, but the basic reasons may be deeply rooted in the owner-labor relationships. It is assumed that the negotiating agents couldn't reduce the gap between the workers and the owners in most of the affected RMG industries due to the absence of Trade Unionism [7].

The RMG sector of Bangladesh, at present, perceived as the foundation of the economy of Bangladesh. It is the second largest garment exporter of the world trading over USD 17 billion worth of clothing (Source: http://www.bgmea.com.bd). In the recent years, the business has blasted and the quantity of industrial facilities occupied with garment creation has expanded rapidly. Bangladesh is currently assessed to have somewhere around four to five thousand garment factories running from extensive first level providers to small factories to a great extent working as subcontractors to greater customers. But in recent couple of years, this industry is confronting danger by insufficient security measures, harassment at

\footnotetext{
variable with a single factor. This is the most common rotation option.

${ }^{4}$ In statistics, regression analysis is a statistical process for estimating the relationships among variables. It includes many techniques for modeling and analyzing several variables, when the focus is on the relationship between a dependent variable and one or more independent variables. More specifically, regression analysis helps one understand how the typical value of the dependent variable (or 'Criterion Variable') changes when any one of the independent variables is varied, while the other independent variables are held fixed.
}

work, awful workplace, and demolishing labor rights [8].

Study shows that mutual understanding among the workers and managers is absent in the RMG sector of Bangladesh. Study also states that high-work load, misbehavior of managers, lower skill and low wages are the notable reasons for high job turnover and social unrest in this sector. Poor relationships between the workers and the supervisors are the main source of conflict in garment industry of Bangladesh. Study finds that there is a growing demand for work life balance among the workers of RMG sector [9]. Study also suggests the improvement of company activities through compliances and finds out a close and positive relationship between compliance and the productivity [10]. Locked exit doors, lack of emergency announcement system, and lack of fire drills are the three worst performers that require immediate attention from the regulators and stakeholders in this sector to ensure the safety and security of the workers [11]. Compliance of RMG factories is a key requirement for most of the reputable global garment buyers. The compliances ensure all labor rights and facilities according to the buyer's Code of Conducts that refers to comply with laws of the country and the Code of Conduct of the buyers. It is the fulfillment or conformity with various International and National Standards that ensures ethical labor practices and health and safety environment at work [12].

Bangladesh garment buyers were heavily shocked by some recent accidents. After the Rana Plaza and Tazreen garments tragedy, the overall basement of the RMG sector of Bangladesh faced a huge jerking. The big buyers started to refuse buying from Bangladesh as long as the safety and security of the workers are not ensured. USA took away the GSP facility that Bangladesh was enjoying for a very long time. The prominent buyer group came together and had several sitting with the concerned ministry to solve this problem. Several treaty and contracts were also made and new rules were implemented. As a result, the situation is changing slowly towards the positive direction.

For regulating the industry in Bangladesh, The Bangladesh Labor Act 2006 amended in 2013 that has been using by the factory inspectors. This law provides some provisions regarding the health and safety of industrial workers. Few noteworthy key points concerning the safety and security of the workers are (i) Cleanliness (ii) Ventilation and Temperature (iii) Dust and Fume (iv) Disposal of Wastes and Effluents (v) Overcrowding (vi) Lighting (vii) Drinking Water (viii) Latrines and Urinals and (xix) Work on or near Machinery in Motion, etc. There are also rules regarding the health and hygiene, welfare, working hours, child labor, women workers, payment of wages, trade union and collective bargaining agent etc. All these rules are not fully implemented till now. But due to the recent tragedies, regulatory bodies and the owners of this sector need to comply with these rules for the future of their businesses. 


\section{Results and Discussions}

The results of this study have been reported in two sub-sections such as, results of factor analysis and results of multiple regression analysis. Factor analysis has been used to identify the factors that are concerned with legal issues applicable in readymade garment industry of Bangladesh. Multiple regression analysis has been used to identify the significant factors or legal aspects concerned with the factors that are important for the improvement of the overall working environment of the garment companies of Bangladesh.

\subsection{Results of Factors Analysis}

Factor analysis shows that there are 14 independent factors concerned with the legal aspects of readymade garment industry of Bangladesh. Factors identified through factor analysis are: leave encashment, employment of child labor for low wages, measures for protecting sexual harassment, following standardized security criteria, fire protection and drill, physical protection of the worker, misbehavior of the managers and co-workers, light protection measures, electric wring, fixtures and control, physical movement and access control, exit and access path, working hours, counseling arrangement and first aid and medical facilities (Table 1). These factors together explain $68.56 \%$ of the variance. This means that the data set used in this study covers $68.56 \%$ percent of the importance. The communalities of the variables also show very high indicating that the variables have strong relationships among them (Appendix 1).

Table 1. Factors and Total Variance Explained

\begin{tabular}{|c|c|c|c|}
\hline \multirow{2}{*}{ Factors } & \multicolumn{3}{|c|}{ Initial Eigenvalues } \\
\hline & Total & $\%$ of Variance & Cumulative \% \\
\hline Leave encashment & 3.503 & 10.009 & 10.009 \\
\hline Employment of child labor for low wages & 2.818 & 8.052 & 18.061 \\
\hline Measures for protecting sexual harassment & 2.165 & 6.186 & 24.247 \\
\hline Following standardized security criteria & 2.036 & 5.816 & 30.063 \\
\hline Fire protection and drill & 1.902 & 5.434 & 35.497 \\
\hline Physical protection of the worker & 1.645 & 4.701 & 40.197 \\
\hline Misbehavior of the managers and co-workers & 1.511 & 4.317 & 44.514 \\
\hline Light protection measures & 1.389 & 3.968 & 48.482 \\
\hline Electric Wring, Fixtures and Control & 1.320 & 3.771 & 52.253 \\
\hline Physical movement and access control & 1.281 & 3.659 & 55.912 \\
\hline Exit and access path & 1.218 & 3.479 & 59.391 \\
\hline Working hours & 1.133 & 3.238 & 62.630 \\
\hline Counseling arrangement & 1.068 & 3.052 & 65.682 \\
\hline First aid and medical facilities & 1.006 & 2.874 & 68.555 \\
\hline
\end{tabular}

Extraction Method: Principal Component Analysis.

The analysis also shows that the factor loadings of each factor are very high indicating that the variables constituted the factor(s) have a very strong association among them and constituted the factor(s). This means the correlations between the variables that are factor loadings, and have very strong relationship to form a group and that is factor (Table 2). 
Table 2. Rotated Component Matrix

\begin{tabular}{|c|c|c|c|c|c|c|c|c|c|c|c|c|c|c|}
\hline \multirow[t]{2}{*}{ Variable No. } & \multicolumn{14}{|c|}{ Factors } \\
\hline & 1 & 2 & 3 & 4 & 5 & 6 & 7 & 8 & 9 & 10 & 11 & 12 & 13 & 14 \\
\hline VAR00004 & .783 & & & & & & & & & & & & & \\
\hline VAR00012 & .705 & & & & & & & & & & & & & \\
\hline VAR00016 & .564 & & & & & & & & & & & & & \\
\hline VAR00007 & & -.747 & & & & & & & & & & & & \\
\hline VAR00001 & & .745 & & & & & & & & & & & & \\
\hline VAR00006 & & .527 & & & & & & & & & & & & \\
\hline VAR00011 & & & .789 & & & & & & & & & & & \\
\hline VAR00005 & & & -.672 & & & & & & & & & & & \\
\hline VAR00010 & & & .533 & & & & & & & & & & & \\
\hline VAR00033 & & & & .702 & & & & & & & & & & \\
\hline VAR00025 & & & & .502 & & & & & & & & & & \\
\hline VAR00030 & & & & .413 & & & & & & & & & & \\
\hline VAR00021 & & & & & .797 & & & & & & & & & \\
\hline VAR00022 & & & & & .727 & & & & & & & & & \\
\hline VAR00026 & & & & & & .785 & & & & & & & & \\
\hline VAR00027 & & & & & & .690 & & & & & & & & \\
\hline VAR00024 & & & & & & .468 & & & & & & & & \\
\hline VAR00009 & & & & & & & .711 & & & & & & & \\
\hline VAR00013 & & & & & & & .707 & & & & & & & \\
\hline VAR00032 & & & & & & & & .773 & & & & & & \\
\hline VAR00031 & & & & & & & & .652 & & & & & & \\
\hline VAR00018 & & & & & & & & & .752 & & & & & \\
\hline VAR00017 & & & & & & & & & .721 & & & & & \\
\hline VAR00035 & & & & & & & & & & .808 & & & & \\
\hline VAR00034 & & & & & & & & & & .564 & & & & \\
\hline VAR00019 & & & & & & & & & & & .722 & & & \\
\hline VAR00020 & & & & & & & & & & & .683 & & & \\
\hline VAR00008 & & & & & & & & & & & & .804 & & \\
\hline VAR00002 & & & & & & & & & & & & -.415 & & \\
\hline VAR00014 & & & & & & & & & & & & & .751 & \\
\hline VAR00003 & & & & & & & & & & & & & .438 & \\
\hline VAR00015 & & & & & & & & & & & & & .384 & \\
\hline VAR00029 & & & & & & & & & & & & & & .747 \\
\hline VAR00028 & & & & & & & & & & & & & & .494 \\
\hline VAR00023 & & & & & & & & & & & & & & -.440 \\
\hline
\end{tabular}

Extraction Method: Principal Component Analysis.

Rotation Method: Varimax with Kaiser Normalization.

a. Rotation converged in 20 iterations. 


\subsection{Results of Multiple Regression Analysis}

The multiple regression analysis shows that the model identified by this study can explain $24.80 \%$ of the dependent variable i.e., the overall application of the labor laws in readymade garment companies in Bangladesh (Table 3).

Table 3. Model Summary

\begin{tabular}{|c|c|c|c|c|c|}
\hline Model & $\mathrm{R}$ & R Square & Adjusted R Square & Std. Error of the Estimate & Durbin-Watson \\
\hline 1 & $.498^{\mathrm{a}}$ & .248 & .201 & .73182 & 1.982 \\
\hline
\end{tabular}

a. Predictors: (Constant), REGR factor score 14 for analysis 1 , REGR factor score 13 for analysis 1 , REGR factor score 12 for analysis 1 , REGR factor score 11 for analysis 1, REGR factor score 10 for analysis 1 , REGR factor score 9 for analysis 1 , REGR factor score 8 for analysis 1 , REGR factor score 7 for analysis 1, REGR factor score 6 for analysis 1 , REGR factor score 5 for analysis 1, REGR factor score 4 for analysis 1 , REGR factor score 3 for analysis 1, REGR factor score 2 for analysis 1, REGR factor score 1 for analysis 1

b. Dependent Variable: Overall

The analysis shows that the Analysis of Variance (ANOVA) is significant at the zero percent level of significance. That means, the factors identified in this analysis are together significantly related to the overall legal environment of readymade garment companies in Bangladesh (Table 4). If there is a change of the factors together there will change the dependent variable that is overall legal environment of the RMG companies of Bangladesh.

Table 4. Analysis of Variance - ANOVA

\begin{tabular}{|c|c|c|c|c|c|c|}
\hline \multicolumn{2}{|c|}{ Model } & Sum of Squares & df & Mean Square & F & Sig. \\
\hline \multirow{2}{*}{1} & Regression & 39.466 & 14 & 2.819 & 5.264 & $.000^{\mathrm{a}}$ \\
\cline { 2 - 7 } & Residual & 119.429 & 223 & .536 & & \\
\cline { 2 - 7 } & Total & 158.895 & 237 & & & \\
\hline
\end{tabular}

a. Predictors: (Constant), REGR factor score 14 for analysis 1, REGR factor score 13 for analysis 1, REGR factor score 12 for analysis 1 , REGR factor score 11 for analysis 1 , REGR factor score 10 for analysis 1 , REGR factor score 9 for analysis 1, REGR factor score 8 for analysis 1 , REGR factor score 7 for analysis 1, REGR factor score 6 for analysis 1, REGR factor score 5 for analysis 1, REGR factor score 4 for analysis 1 , REGR factor score 3 for analysis 1 , REGR factor score 2 for analysis 1, REGR factor score 1 for analysis 1

b. Dependent Variable: Overall

The regression analysis also shows that the significant relationships of the factors with the overall legal environment of the readymade garment industry of Bangladesh. The results also show that the factors such as, measures for protecting sexual harassment, physical movement and access control, exit and access path, working hours and counseling arrangement are individually significantly related to the overall legal environment of the industry (Table 5). These factors are in very poor conditions in the readymade garment companies of Bangladesh which are to be improved. The factors such as, leave encashment, employment of child labor for low wages, following standardized security criteria, fire protection and drill, physical protection of the worker, misbehavior of the managers and co-workers, protection measures, electric wring, fixtures and control, and first aid and medical facilities are not significantly related to the overall legal environment of the industry. The conditions of these factors are, perhaps, in a situation that is acceptable to the readymade garment workers of Bangladesh. 
Table 5. Coefficients ${ }^{a}$

\begin{tabular}{|c|c|c|c|c|c|c|}
\hline & \multirow[t]{2}{*}{ Model } & \multicolumn{2}{|c|}{ Unstandardized Coefficients } & \multirow{2}{*}{$\begin{array}{c}\begin{array}{c}\text { Standardized } \\
\text { Coefficients }\end{array} \\
\text { Beta } \\
\end{array}$} & \multirow[t]{2}{*}{$\mathrm{t}$} & \multirow[t]{2}{*}{ Sig. } \\
\hline & & B & Std. Error & & & \\
\hline \multirow{15}{*}{1} & (Constant) & 4.021 & .047 & & 84.766 & .000 \\
\hline & Leave encashment & .070 & .048 & .085 & 1.466 & .144 \\
\hline & Employment of child labor for low wages & .069 & .048 & .085 & 1.458 & .146 \\
\hline & Measures for protecting sexual harassment & .132 & .048 & .162 & 2.783 & .006 \\
\hline & Following standardized security criteria & -.033 & .048 & -.041 & -.701 & .484 \\
\hline & Fire protection and drill & -.068 & .048 & -.082 & -1.420 & .157 \\
\hline & Physical protection of the worker & -.062 & .048 & -.076 & -1.311 & .191 \\
\hline & $\begin{array}{l}\text { Misbehavior of the managers and } \\
\text { co-workers }\end{array}$ & -.052 & .048 & -.063 & -1.085 & .279 \\
\hline & Light protection measures & .001 & .048 & .001 & .024 & .981 \\
\hline & Electric Wring, Fixtures and Control & -.054 & .048 & -.066 & -1.134 & .258 \\
\hline & Physical movement and access control & .189 & .048 & .231 & 3.981 & .000 \\
\hline & Exit and access path & .230 & .048 & .281 & 4.832 & .000 \\
\hline & Working hours & .082 & .048 & .101 & 1.733 & .084 \\
\hline & Counseling arrangement & .126 & .048 & .153 & 2.644 & .009 \\
\hline & First aid and medical facilities & .114 & .048 & .140 & 2.407 & .017 \\
\hline
\end{tabular}

a. Dependent Variable: Overall

Table 6 shows that the mean value of the factors are very high and the standard deviation is less than one indicating that the mean value has strong meaning. The Normal P-P Plot of regression standardized residual also shows the good shape of the model (Figure 1).

Table 6. Residuals Statistics ${ }^{\mathrm{a}}$

\begin{tabular}{|c|c|c|c|c|c|}
\hline & Minimum & Maximum & Mean & Std. Deviation & N \\
\hline Predicted Value & 2.3403 & 4.9190 & 4.0210 & .40807 & 238 \\
\hline Residual & -2.51300 & 1.64064 & .00000 & .70987 & 238 \\
\hline Std. Predicted Value & -4.119 & 2.201 & .000 & 1.000 & 238 \\
\hline Std. Residual & -3.434 & 2.242 & .000 & .970 & 238 \\
\hline
\end{tabular}

a. Dependent Variable: Overall

Dependent Variable: Overall

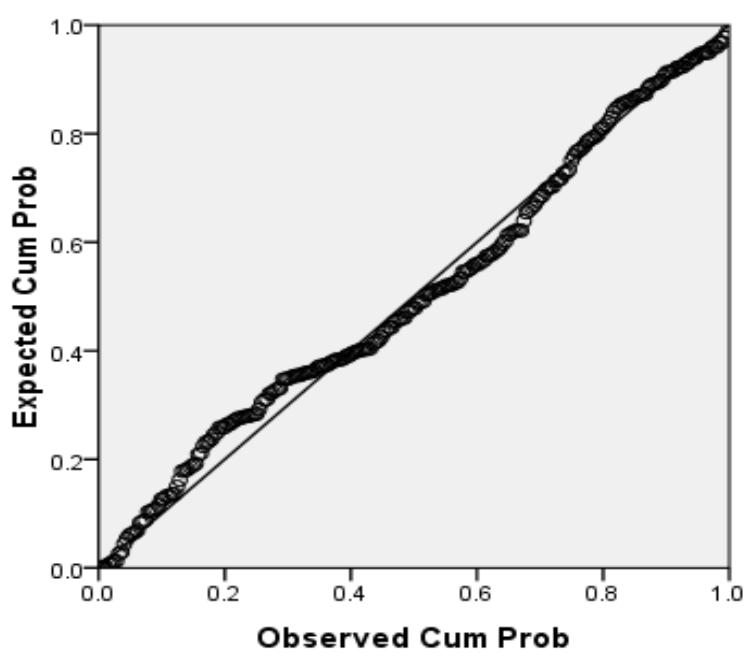

Figure 1. Normal P-P Plot of regression standardized residual

\section{Conclusions and Recommendations}

This study was conducted to evaluate the application of legal and other compliances of readymade garment industry of Bangladesh. As readymade garment industry of Bangladesh is a fully export oriented, it requires addressing national and international compliances strictly. Specifically, the legal compliances in this sector are required due to sustain and attract existing international buyers, meet government requirements, ensure benefits of the workers, maintaining good relationships between workers and management, ensure environmental safety, and confirm social accountability[13]. This study shows that there are fourteen areas concerning legal and other compliances in readymade garment industry of Bangladesh such as, leave encashment, employment of child labor for low wages, measures for protecting sexual harassment, following standardized security criteria, fire protection and drill, physical protection of the worker, misbehavior of the 
managers and co-workers, light protection measures, electric wring, fixtures and control, physical movement and access control, exit and access path, working hours, counseling arrangement and first aid and medical facilities that are to be addressed by the RMG company authority to ensure and address legal and other requirements of this industry. These factors are together significantly related to the improvement of the legal and other of environment of this industry in Bangladesh.

Factors such as, appropriate measures for protecting sexual harassment at and outside work, physical movement and access control exit and access path of the company, employ working hours, and counseling arrangements in the readymade garment companies of Bangladesh are significantly related to the overall legal and other environments of the RMG industry. This indicates that if these factors are addressed properly the overall legal and other environment of the readymade garment industry will be changed and improved. These findings support the findings of the studies conducted earlier in this regard. The factors including leave encashment, employment of child labor for low wages, standardized security criteria, fire protection and drill, physical protection of the worker, misbehavior of the managers and co-workers, light protection measures, electric wring, fixtures and control, and first aid and medical facilities are found not significantly related to the overall legal and other environment of the RMG industry. These areas of legal and other compliances are acceptable to the workers of the readymade garment industry in Bangladesh. This study only included the workers in its sample respondents. However, there is also an ample scope to conduct further study by taking managers and owners as sample respondents and more variables into account that may result in more precise findings concerning the application of the legal and other compliances in the readymade garment industry of Bangladesh.

\section{Appendices}

\section{Appendix 1. Communalities of the Variables}

\begin{tabular}{|c|c|c|}
\hline Variable No. & Name of the Variables & Extraction \\
\hline VAR00001 & Payment of wages is hardly on time in my company & .681 \\
\hline VAR00002 & Granting Leave is a rare opportunity in my company & .652 \\
\hline VAR00003 & Festival bonus, Gratuity \& Provident Fund are not given on time in my company & .609 \\
\hline VAR00004 & Leave encashment is absent in the company & .695 \\
\hline VAR00005 & In case of Termination, Retrenchment, Dismissal, Discharge proper rules are followed in the company & .738 \\
\hline VAR00006 & Workers Association or Collective Bargaining is not allowed in the company & .644 \\
\hline VAR00007 & Child labor is often used to work in the company & .752 \\
\hline VAR00008 & Working hour is too long & 699 \\
\hline VAR00009 & Disciplinary action is hardly taken for misbehave with the workers in the company & .737 \\
\hline VAR00010 & Misbehavior and abusive words are often used by our supervisors and managers & .665 \\
\hline VAR00011 & Sexual harassment is regular happening inside and outside in the company & .710 \\
\hline VAR00012 & Threatening by the manager is a normal practice in my company & .709 \\
\hline VAR00013 & Discrimination or disrespect towards female workers in a normal practice & .709 \\
\hline VAR00014 & Counseling department is not active in the company & .690 \\
\hline VAR00015 & Child care, canteen, dining hall facilities are poor in the company & .605 \\
\hline VAR00016 & Safety committee, safety policy and emergency requirements are hardly met by the company authority & .719 \\
\hline VAR00017 & Chemical safety is not up to the standard & .719 \\
\hline VAR00018 & Electric Wring, Fixtures and control at work place is not safe & .729 \\
\hline VAR00019 & Exit \& Access path is very much narrow & .604 \\
\hline VAR00020 & Emergency Exit is not maintained properly & .688 \\
\hline VAR00021 & Fire Protection and Drill are not maintained properly & .703 \\
\hline
\end{tabular}




\begin{tabular}{|c|l|c|}
\hline VAR00022 & Housekeeping \& general work environment is not comfortable to work & .659 \\
\hline VAR00023 & Machines \& Equipment safety protection is inadequate & .697 \\
\hline VAR00024 & $\begin{array}{l}\text { My company uses the materials like Flammable, Liquids, Oxidizing, Chemicals in manufacturing but } \\
\text { not properly safe guarded }\end{array}$ & .651 \\
\hline VAR00025 & Toxic materials are not safely used & .624 \\
\hline VAR00026 & Employee's physical protection is a concern here in the company & .750 \\
\hline VAR00027 & Personal protective Equipments are old and inadequate & .751 \\
\hline VAR00028 & There is no protection of dust and fume in my company & .716 \\
\hline VAR00029 & First Aid \& Medical facilities are not available in the company & .678 \\
\hline VAR00030 & Noise disturbs me in work & .712 \\
\hline VAR00031 & Solid wastage disposal system is not good in my company & .687 \\
\hline VAR00032 & Excessive light protection is inappropriate in my company & .690 \\
\hline VAR00033 & $\begin{array}{l}\text { Standardized security criteria - C-TPAT is not followed in my company (C-TPAT security criteria is to } \\
\text { enhance the integrity of the shipment at point of origin, assembly or manufacturing) }\end{array}$ & $\begin{array}{l}\text { 7 point check (analyze hazards, determine control points, establish limits for critical points, establish } \\
\text { monitoring procedures for critical control, establish corrective actions, establish verification } \\
\text { procedures, and establish a record system) is not used in my company }\end{array}$ \\
\hline VAR00034 & $\begin{array}{l}\text { Physical Movement Access control is not proper } \\
.681\end{array}$ \\
\hline
\end{tabular}

Extraction Method: Principal Component Analysis.

\section{Appendix 2. Interview Guide}

\section{Scale: Strongly Disagree $1 \rightarrow 2 \rightarrow 3 \rightarrow 4 \rightarrow 5 \rightarrow$ Strongly Agree}

Be sure to keep the statement in mind when deciding how you feel about application of legal aspects of your job and working conditions. Do this for all statements. Answer every item. Do not turn back to previous statements. Be frank. Give a true picture of your agreements or disagreements about the present legal conditions where you work now.

\begin{tabular}{|c|l|c|c|c|c|c|}
\hline SI \# & Statements & \multicolumn{3}{|c|}{ SD SA } \\
\hline 1. & Payment of wages is hardly on time in my company & 2 & 3 & 4 & 5 \\
\hline 2. & Granting Leave is a rare opportunity in my company & 1 & 2 & 3 & 4 & 5 \\
\hline 3. & Festival bonus, Gratuity \& Provident Fund are not given on time in my company & 1 & 2 & 3 & 4 & 5 \\
\hline 4. & Leave encashment is absent in the company & 1 & 2 & 3 & 4 & 5 \\
\hline 5. & In case of Termination, Retrenchment, Dismissal, Discharge proper rules are followed in the & 1 & 2 & 3 & 4 & 5 \\
\hline 6. & Workers Association or Collective Bargaining is not allowed in the company & 1 & 2 & 3 & 4 & 5 \\
\hline 7. & Child labor is often used to work in the company & 1 & 2 & 3 & 4 & 5 \\
\hline 8. & Working hour is too long & 1 & 2 & 3 & 4 & 5 \\
\hline 9. & Disciplinary action is hardly taken for misbehave with the workers in the company & 1 & 2 & 3 & 4 & 5 \\
\hline 10. & Misbehavior and abusive words are often used by our supervisors and managers & 1 & 2 & 3 & 4 & 5 \\
\hline 11. & Sexual harassment is regular happening inside and outside in the company & 1 & 2 & 3 & 4 & 5 \\
\hline 12. & Threatening by the manager is a normal practice in my company & 1 & 2 & 3 & 4 & 5 \\
\hline 13. & Discrimination or disrespect towards female workers in a normal practice & 1 & 2 & 3 & 4 & 5 \\
\hline 14. & Counseling department is not active in the company & 1 & 2 & 3 & 4 & 5 \\
\hline 15. & Child care, canteen, dining hall facilities are poor in the company & 1 & 2 & 3 & 4 & 5 \\
\hline 16. & Safety committee, safety policy and emergency requirements are hardly met by the company & 1 & 2 & 3 & 4 & 5 \\
\hline 17. & Chemical safety is not up to the standard & 1 & 2 & 3 & 4 & 5 \\
\hline 18. & Electric Wring, Fixtures and control at work place is not safe & 1 & 2 & 3 & 4 & 5 \\
\hline 19. & Exit \& Access path is very much narrow & 1 & 2 & 3 & 4 & 5 \\
\hline 20. & Emergency Exit is not maintained properly & 1 & 2 & 3 & 4 & 5 \\
\hline & & & 5
\end{tabular}




\begin{tabular}{|c|c|c|c|c|c|c|}
\hline 21. & Fire Protection and Drill are not maintained properly & 1 & 2 & 3 & 4 & 5 \\
\hline 22. & Housekeeping \& general work environment is not comfortable to work & 1 & 2 & 3 & 4 & 5 \\
\hline 23. & Machines \& Equipment safety protection is inadequate & 1 & 2 & 3 & 4 & 5 \\
\hline 24. & $\begin{array}{l}\text { My company uses the materials like Flammable, Liquids, Oxidizing, Chemicals in } \\
\text { manufacturing but not properly safe guarded }\end{array}$ & 1 & 2 & 3 & 4 & 5 \\
\hline 25. & Toxic materials are not safely used & 1 & 2 & 3 & 4 & 5 \\
\hline 26. & Employee's physical protection is a concern here in the company & 1 & 2 & 3 & 4 & 5 \\
\hline 27. & All personal protective Equipment is old and inadequate & 1 & 2 & 3 & 4 & 5 \\
\hline 28. & There is no protection of dust and fume in my company & 1 & 2 & 3 & 4 & 5 \\
\hline 29. & First Aid \& Medical facilities are not available in the company & 1 & 2 & 3 & 4 & 5 \\
\hline 30. & Noise disturbs me in work & 1 & 2 & 3 & 4 & 5 \\
\hline 31. & Solid wastage disposal system is not good in my company & 1 & 2 & 3 & 4 & 5 \\
\hline 32. & Excessive light protection is inappropriate in my company & 1 & 2 & 3 & 4 & 5 \\
\hline 33. & $\begin{array}{l}\text { Standardized security criteria - C-TPAT is not followed in my company (C-TPAT security } \\
\text { criteria is to enhance the integrity of the shipment at point of origin, assembly or manufacturing) }\end{array}$ & 1 & 2 & 3 & 4 & 5 \\
\hline 34. & $\begin{array}{l}7 \text { point check (analyze hazards, determine control points, establish limits for critical points, } \\
\text { establish monitoring procedures for critical control, establish corrective actions, establish } \\
\text { verification procedures, and establish a record system) is not used in my company }\end{array}$ & 1 & 2 & 3 & 4 & 5 \\
\hline \multirow[t]{4}{*}{35.} & Physical Movement Access control is not proper & 1 & 2 & 3 & 4 & 5 \\
\hline & Chemical Safety Awareness Training is not regularly given in my company & 1 & 2 & 3 & 4 & 5 \\
\hline & Social Awareness Training is not regularly given in my company & 1 & 2 & 3 & 4 & 5 \\
\hline & Health \& Safety Awareness Training is not regularly given in my company & 1 & 2 & 3 & 4 & 5 \\
\hline 36 & As a whole, I think my company does not maintain rules and compliances properly. & 1 & 2 & 3 & 4 & 5 \\
\hline
\end{tabular}

\section{REFERENCES}

[1] Islam N, Bari Chowdhuri AS. Socio-economic factors of readymade garments workers in Bangladesh. D.U. Journal of Marketing. 2016. 15.

[2] Kabeer N, Mahmud S. Globalization, gender and poverty: Bangladeshi women workers in export and local markets. Journal of international development. 2004 Jan 1; 16(1):93-109.

[3] Yamane T. Statistics - An Introductory Analysis, 2nd Edition. New York: Harper and Row. 1967.

[4] Hair JF, Black WC, Babin BJ, Anderson RE, Tatham RL. Multivariate data analysis. Upper Saddle River, NJ: Prentice hall; 1998 March.

[5] Malhotra NK. Marketing research: An applied orientation, 5/e. Pearson Education India; 2008.

[6] Hossain M, Mathbor GM, Semenza R. Feminization and Labor Vulnerability in Global Manufacturing Industries: Does Gendered Discourse Matter? Asian Social Work and Policy Review. 2013 Oct 1; 7(3):197-212.

[7] Ahmed S, Raihan MZ, Islam N. Labor Unrest in the Readymade Garment Industry of Bangladesh. International Journal of Business and Management. 2013. 8(15).

[8] Morshed MM. A study on labour rights implementation in readymade garment (RMG) industry in Bangladesh: Bridging the gap between theory and practice. 2007. A thesis submitted in partial fulfillment of the requirements for the award of the degree Master of Social Change and Development (Honours), The University of Wollongong, Australia.

[9] Hossan CG, Sarker MA, Afroze R. Recent Unrest in the RMG Sector of Bangladesh: Is this an Outcome of Poor Labour Practices? International Journal of Business and Management. 2012 Jan. 31; 7(3):206.

[10] Rahman MA, Hossain MS. Compliance practices in garment industries in Dhaka city. Journal of Business and Technology (Dhaka). 2010; 5(2):71-87.

[11] Wadud Z, Huda FY, Ahmed NU. Assessment of fire risk in the readymade garment industry in Dhaka, Bangladesh. Fire Technology. 2014 Sep 1; 50(5):1127-45.

[12] AHAMED F. Child labour and Bangladesh: To what extent can Bangladesh remove child labour particularly in the Bangladesh Ready-made Garment (RMG) sector? International NGO Journal. 2013 Feb 28; 8(2):31-37. Available online at http://www.academicjournals.org/INGOJ

[13] Mariani RD. Working conditions in the Bangladeshi garment sector: Social dialogue and compliance. 2013.Website:

https://www3.fairwear.org/ul/cms/fck-uploaded/documents /countrystudies/bangladesh/WorkingconditionsintheBangla deshigarmentsectorSocialdialogueandcompliance.pdf 